\title{
Accessibility-oriented development
}

Robbin Deboosere

School of Urban Planning

McGill University

E-mail: robbin.deboosere@mail.mcgill.ca

\section{David Levinson}

School of Civil Engineering

University of Sydney

E-mail: david.levinson@sydney.edu.au

\section{Ahmed M. El-Geneidy}

School of Urban Planning

McGill University

E-mail: ahmed.elgeneidy@mcgill.ca

4725 words +1725 words references, and 3 tables and 4 figures (8200 words total)

Paper submitted for presentation at the $97^{\text {th }}$ Transportation Research Board Annual Meeting

July 2017 


\begin{abstract}
Municipal governments worldwide have been pursuing transit-oriented development (TOD) strategies in order to increase transit ridership, curb traffic congestion, and rejuvenate urban neighborhoods. In many cities, however, development of planned sites around transit stations has been close to non-existent, due to, among other reasons, a lack of coordination between transit investments and land use at the regional scale. Furthermore, the ability to access transit differs from the ability to access destinations that people care about. Reframing transit-oriented development as accessibility-oriented development (AOD) can aid the process of creating functional connections between neighborhoods and the rest of the region, and maximize benefits from transport investments. AOD is a strategy that balances accessibility to employment and the labor force in order to foster an environment conducive to development. AOD areas are thus defined as having higher than average accessibility to employment opportunities and/or the labor force; such accessibility levels are expected to increase the quality of life of residents living in these areas by reducing their commute time and encouraging faster economic development. To quantify the benefits of AOD, accessibility to employment and the labor force are calculated in the Greater Toronto and Hamilton Area, Canada in 2001 and 2011. Cross-sectional and temporal regressions are then performed to predict average commute times and development occurring in AOD areas and across the region. Results show that AOD neighborhoods with high accessibility to jobs and low accessibility to the labor force have the lowest commute times in the region, while the relationship also holds for changes in average commute time between the studied time periods. In addition, both accessibility to jobs and accessibility to the labor force are associated with changes in development, as areas with high accessibility to jobs and the labor force attract more development. In order to realize the full benefits of planned transit investments, planning professionals and policy makers alike should therefore leverage accessibility as a tool to direct development in their cities, and concentrate on developing neighbourhoods with an AOD approach in mind.
\end{abstract}

Keywords: Transit-oriented development, accessibility, travel behavior, land use 


\section{INTRODUCTION}

Municipal governments worldwide have been aggressively pursuing transit-oriented development (TOD) strategies in order to increase transit ridership (1-4). For years, TOD has been receiving increased attention by scholars and transport professionals alike (5-7). Neighborhoods are often defined as TODs when they are situated close to transit, allow for higher density development, and possess diversified land uses $(8 ; 9)$. TOD therefore not only involves the construction of public transport infrastructure, but also requires the integration of transport and land use $(10 ; 11)$; in this way, TOD intends to achieve a holistic way of compact urban development, enabled by supporting public sector policies such as zoning and tax incentives. As TODs usually also encompass increased attention to urban design, livable spaces and walkability, the demand for housing in TOD areas results in increased premiums for homes located in TODs (12-14). Residents in these areas have also been found to rely more on transit and active modes of transport, seemingly fulfilling the promises of TOD $(9 ; 15)$, although the relationship between TOD and transit use has been found to differ between trip motives (16), and not the ' $\mathrm{T}$ ' in TOD, but rather limited parking availability and higher density may be causing the observed decrease in car use (17).

Areas planned as TOD, however, do not always function as foreseen; in many cities, development on planned sites has been close to non-existent. One potential reason is that the connection between the (planned) transit investment and land use at both the local and regional scales are often overlooked. At the local scale, transit-adjacent developments (TADs) fail to take advantage of their proximity to transit and bring almost none of the benefits normally associated with TODs (13). The often physical nature of the definition of TODs ('density near transit') contributes to this problem (18). In other cases, local housing and commerce are functionally integrated with the public transport system, but planners have failed to consider regional access to opportunities. As travel patterns are mostly determined by region-wide levels of accessibility, such TODs fail to increase transit usage $(17 ; 19)$. We contend that many of these issues can be alleviated by introducing the concept of accessibility-oriented development (AOD).

The process of creating functional connections between neighborhoods and the rest of the region can be improved by focusing on AOD, which maximizes benefits from transport investments. Accessibility, or the ease of reaching destinations, is an easy-to-use measure that can help unravel the intricacies involved in combined land use and transport planning in the minds of planning professionals and urban decision makers (20). We define accessibility-oriented development as a strategy that balances accessibility to employment and the labor force in order to foster an environment conducive to development. AOD areas are therefore characterized by higher than average accessibility to jobs and/or the labor force. We hypothesize that transport investments made on the principles of AOD will result in natural development occurring in the targeted neighborhoods, and, through lower commute times, a better quality of life for residents.

The rest of this paper is organised as follows. Section 2 describes the concept of accessibility, and links it with economic development, after which AOD is defined more thoroughly. Section 3 tests hypotheses about AOD in a case study of the Greater Toronto and Hamilton Area, Canada, using accessibility to jobs and the labor force in 2001 and 2011. Section 4 then concludes the 
paper and provides policy recommendations for the implementation of AOD and directions for future study.

\section{ACCESSIBILITY-ORIENTED DEVELOPMENT}

\subsection{Accessibility}

Accessibility is a comprehensive measure of the land use and transport interaction in a region and illustrates the ease of reaching destinations $(21 ; 22)$. Accessibility was first defined by Hansen (23), who used the measure to develop a residential land use model, under the assumption that accessibility was a main driver of residential development. This paper tries to build on this seminal work by testing the relationship between accessibility and development across different modes in a current-day environment in Canada.

Two common measures of accessibility exist. Cumulative opportunity measures of accessibility compute how many opportunities an individual can reach within a predefined time-limit (24), whereas gravity-based (or, equivalently, time-weighted cumulative opportunity) accessibility measures relax the assumption that people only travel until an arbitrary time limit, and discount opportunities by distance (23). While gravity-based measures of accessibility more realistically model behavior, they require the prediction of a distance decay function and are thus more difficult to calculate, communicate, and compare across studies (25).

The concept of accessibility has been widely used to shed light on the benefits resulting from land use and transport systems. These benefits range from higher land values (26), over smaller risks of social exclusion $(27)$, to shorter unemployment duration $(28 ; 29)$ and increased odds of firm birth in areas with high accessibility levels (30). Furthermore, accessibility by public transport has been shown to be related to increased transit modal choice (31). Accordingly, to measure how these benefits are distributed across different socio-economic groups, accessibility has also been used to examine the equity of the transport and land use interaction (32-36). However, even though the connection between transport and economic development has been extensively investigated, little research has coupled the concept of accessibility with development.

\subsection{Transport, accessibility and economic development}

A large body of literature has focused on establishing a theoretical framework between transport and subsequent land use patterns and development. Kain (37) and later Alonso (38) extended the model developed by von Thünen representing land value as a function of distance to a central business district, and argued that land values in turn influence land use patterns. The bid-rent theory developed by Alonso (38), and later extended by many other scholars (see for example (Anas and Moses (39); Mills (40))), offers households a trade-off between transport cost and rent, resulting in higher land values for more central locations. As land near the CBD is more expensive according to the bid-rent theory, competition will favor more intensive development in this central location. Changes in the transport system are therefore said to result in changes in land use patterns through the intermediating effect of commute duration and land values. 
In a similar vein as the urban economics scholars before them, transport researchers focusing on accessibility have linked transport changes to changing land use and activity patterns $(25 ; 41$; 42). Many governments and transit agencies have also acknowledged the link between transport and economic development (43), and many cities and regions worldwide are looking to capitalize on this link through land value capture (44-46).

Public sector policy, and economic and population growth play vital roles in determining the viability of the links presented above $(42 ; 47)$. Supporting tax and land use policies, for example, can expedite how changes in accessibility impact land use, while the general economic climate is a vital aspect in determining whether or not development will occur on the site. Banister and Berechman (48) argue that coordination between regional and municipal agencies, combined with favorable economic circumstances are pre-conditions for the association between transport and development to occur.

The links presented above have subsequently been investigated in a myriad of empirical studies. Levinson (49) examines the association between accessibility measures and commute duration. In a cross-sectional study, he finds that, for origins, accessibility to employment opportunities is inversely related to average commute duration, while accessibility to housing is positively correlated to average commute time. The association between accessibility and land values is considered by El-Geneidy, van Lierop and Wasfi (26), Franklin and Waddell (50) and Martínez and Viegas (51), among others, who find that higher accessibility levels are related to increased home values. Iacono and Levinson (52), on the other hand, conclude that, although homes in neighborhoods with higher accessibility levels command value premiums, the relationship no longer holds for improvements in accessibility. Maturity of the transport network is said to be causing this effect. Similarly, Du and Mulley (53) find that the effects of accessibility on home values depend on location and the accessibility level of the neighborhood.

The relationship between transport investments and economic benefits is assessed by Banister and Berechman (48), Mejia-Dorantes, Paez and Vassallo (54), and Padeiro (55), among others. They find that transport infrastructure changes are related to economic development, although the relationship varies by location and occurs mostly in sectors showing large agglomeration economies, such as finance and real estate. Mejia-Dorantes, Paez and Vassallo (54) show that distance to subway stations is a key determinant of firm location, while Padeiro (55), in a case study of small municipalities in the Île-de-France region, concludes that the presence of train stations does not significantly affect job growth, whereas the presence of a highway is only a significant predictor of growth for the smallest municipalities.

Ozbay, Ozmen-Ertekin and Berechman (56) investigate the relationship between accessibility and economic development in the New York - New Jersey region and find that accessibility changes are related to changes in employment growth (and therefore land use). In a case study of motorways in Portugal, Holl (30) develops a measure of market access similar to a gravitybased measure of accessibility to the labor force, and concludes that the odds of firm birth are higher for several manufacturing and construction sectors when market access is larger. Applied to a case study in Chicago, Warade (47) develops a quasi-integrated land use and transport model and concludes that higher accessibility to jobs is associated with increased household density, 
whereas higher accessibility to workers is related to increased job density. Shen, de Abreu e Silva and Martínez (57) examine the effects of local and regional accessibility on development near the Atocha station in Madrid, Spain. The authors find that accessibility, at both the city and country level, is a significant predictor in determining land cover change. Farber and Grandez Marino (58) acknowledge the strong association between accessibility and development, and generate a typology of planned stations in the Greater Toronto and Hamilton Area based on development potential around the station and the projected change in accessibility. The authors conclude that there exists considerable mismatch between development potential and large predicted accessibility changes. This conclusion highlights the need for accessibility considerations when investing considerable amounts in new transport infrastructure, in order to realize the full benefits of the planned investment. We contend that the introduction of AOD can greatly benefit this process.

\subsection{Accessibility-oriented development}

Based on the theoretical accessibility and development framework and the empirical literature presented above, we define accessibility-oriented development as a strategy that balances accessibility to employment opportunities and the labor force in order to foster an environment conducive to development. This differs from the traditional 'jobs-housing balance' literature by avoiding the use of arbitrary municipal boundaries, and instead considers the relationship between access to jobs and access to competing workers $(49 ; 59-61)$. Three AOD areas can be defined: (1) areas with high accessibility to both employment and the labor force, (2) neighborhoods with high accessibility levels to jobs and low access to the labor force, and, inversely, (3) neighborhoods with high accessibility to workers and low access to jobs.

Unlike transit-adjacent development, AOD explicitly considers the functional connections between transport infrastructure and surrounding local and regional land use. The failure of transit-adjacent development lies in its inability to leverage the link between transport and (regional) accessibility. The mechanisms presented above are therefore not set in motion, resulting in an unchanging land use pattern and no further development of the area. As these shortcomings of TODs are negated by adopting AOD, we hypothesise that accessibility-oriented development brings the following benefits:

Hypothesis 1: Residents in neighborhoods with high accessibility to employment and low accessibility to the labor force experience the lowest average commute duration, and vice versa.

Hypothesis 2: Neighborhoods with high accessibility levels to both employment and the labor force attract more development. High accessibility to employment invites residential and commercial development by influencing home location choice and leveraging agglomeration economies, while high accessibility to the labor force draws in more businesses.

Through the mechanisms presented in the theoretical framework, we propose that targeting key areas by increasing job accessibility can help shorten commute times and attract residents to these neighborhoods, helping these regions to rejuvenate. Other areas should be designed to allow for maximum accessibility to the labor force, which would provide incentives for firms in the service and retail sectors to locate themselves in these neighborhoods, in order to minimize 
their employees' or customers' travel times and benefit from agglomeration economies. This in turn would lower commute times. Development would therefore occur naturally in AOD sectors, once the starting conditions are set by adequate policy.

\section{CASE STUDY: THE GREATER TORONTO AND HAMILTON AREA}

To confirm the two hypotheses about AOD, a case study is performed in the Greater Toronto and Hamilton Area, Canada (GTHA) between 2001 and 2011. The GTHA is the largest metropolitan agglomeration in Canada, housing 6.6 million residents in 2011 and comprises the Hamilton, Toronto and Oshawa census metropolitan areas (CMA). Population in the region increased by over 1 million inhabitants during the study period, while the total number of jobs grew from 2.9 to 3.5 million (62). Between 2001 and 2011, the transport network in the region underwent substantial changes: a new subway line was opened in 2002, and several new train stations were constructed. A context map of the GTHA can be seen in figure 2.

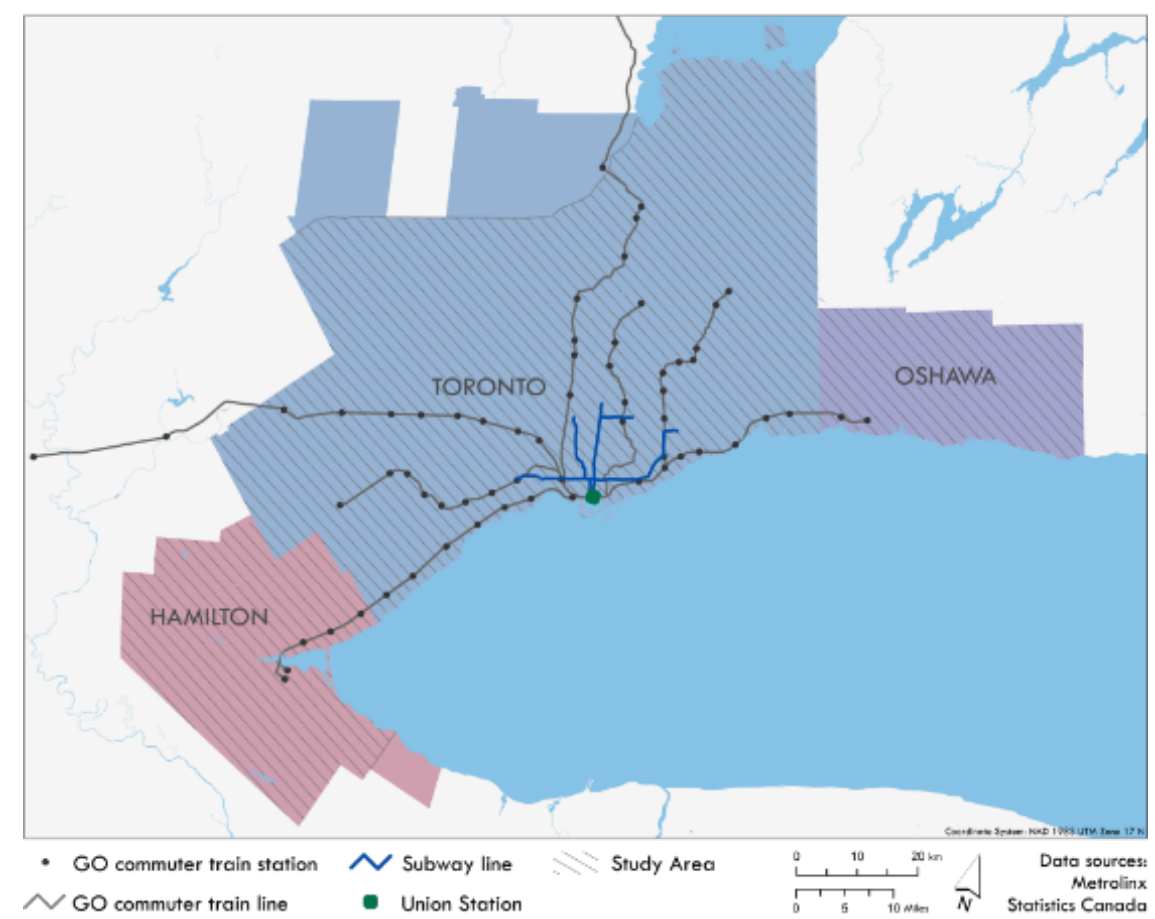

FIGURE 1 Context map of the Greater Toronto and Hamilton Area

\subsection{Data}

Data from Metrolinx and Statistics Canada were used to generate cumulative accessibility by both car and public transport (PT) to employment opportunities and the labor force. To reflect the commuting behavior of an average individual, car accessibility was calculated for a time limit of 30 minutes, while accessibility by transit was computed for a 45 minute time limit (63). As the data sources for the number of jobs differed between 2001 and 2011, a relative measure of accessibility was calculated by dividing the total number of jobs (workers) reachable within the time limit by the total number of jobs (workers) in the region. Accessibility can then be interpreted as the percentage of all jobs (workers) in the region an individual can access: a value 
of 1 signifies that all jobs (workers) can be reached within the time limit (30 or 45 minutes depending on the mode), while a value of 0.25 indicates that $25 \%$ of all jobs (workers) can be reached within the set time frame.

To test the two AOD hypotheses, commute duration for 2011 was gathered from Statistics Canada, while commute duration in 2001 was calculated based on OD flows and travel times. Development was subsequently measured by the percentage of open area in the census tract (measured as the area not used for residential, commercial, industrial, governmental, or park purposes). The AOD assumptions were then examined through five regression models, relating commute duration, open area, and job and population density with accessibility and accessibility changes.

\subsection{Accessibility in the GTHA}

Figure 3 shows normalized accessibility levels by car to employment opportunities and the labor force. Accessibility to jobs by car is highest in downtown Toronto, while the highest accessibility levels to the labor force are present in neighborhoods that form a ring around the Toronto CBD. This reflects that the central business district houses fewer people than the area immediately surrounding it, and that it is easier for residents of the outskirts of the region to travel to these suburban locations than to the city center. Between 2001 and 2011, accessibility to workers increased substantially more across the study area than accessibility to jobs. According to the second AOD hypothesis, the suburban locations with high accessibility to the labor force should experience more job creation during the study period, providing that the benefits of access to labor outweigh those of existing agglomeration economies of access to existing businesses (operationalized as access to jobs).

Accessibility levels by public transport are shown in figure 4. Accessibility by transit is considerably lower than accessibility by car, even with an extra 15 minutes of travel time, in both years, for access to jobs and workers. High accessibility by transit is mainly present in downtown Toronto and in areas located in close proximity to the GO commuter rail lines. Unlike the spatial patterns present in accessibility by car, the two accessibility measures for public transport, to jobs and workers, are highly correlated (a correlation of 0.95). In 2011, suburban areas located next to the public transport network have seen increases in accessibility, while areas with traditionally high access (such as downtown Toronto) have seen a small decrease in access, which might be related to suburbanization of jobs, combined with investments made in the GO commuter train network during the study period. 

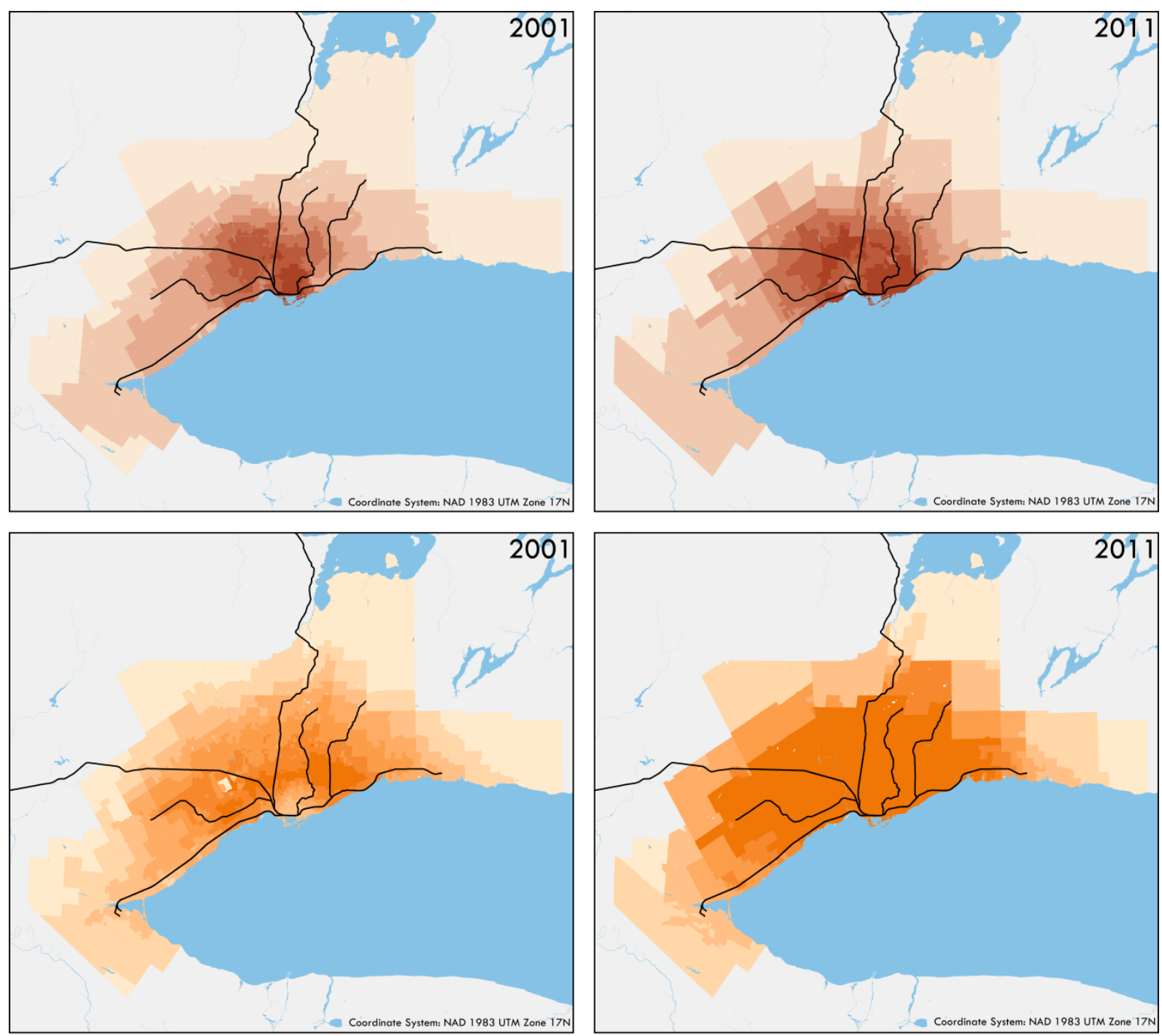

Accessibility to jobs by car - low to high D Accessibility to labor force by car - low to high

Metrolinx Statistics Canada

FIGURE 2 Accessibility to jobs and the labor force by ca 

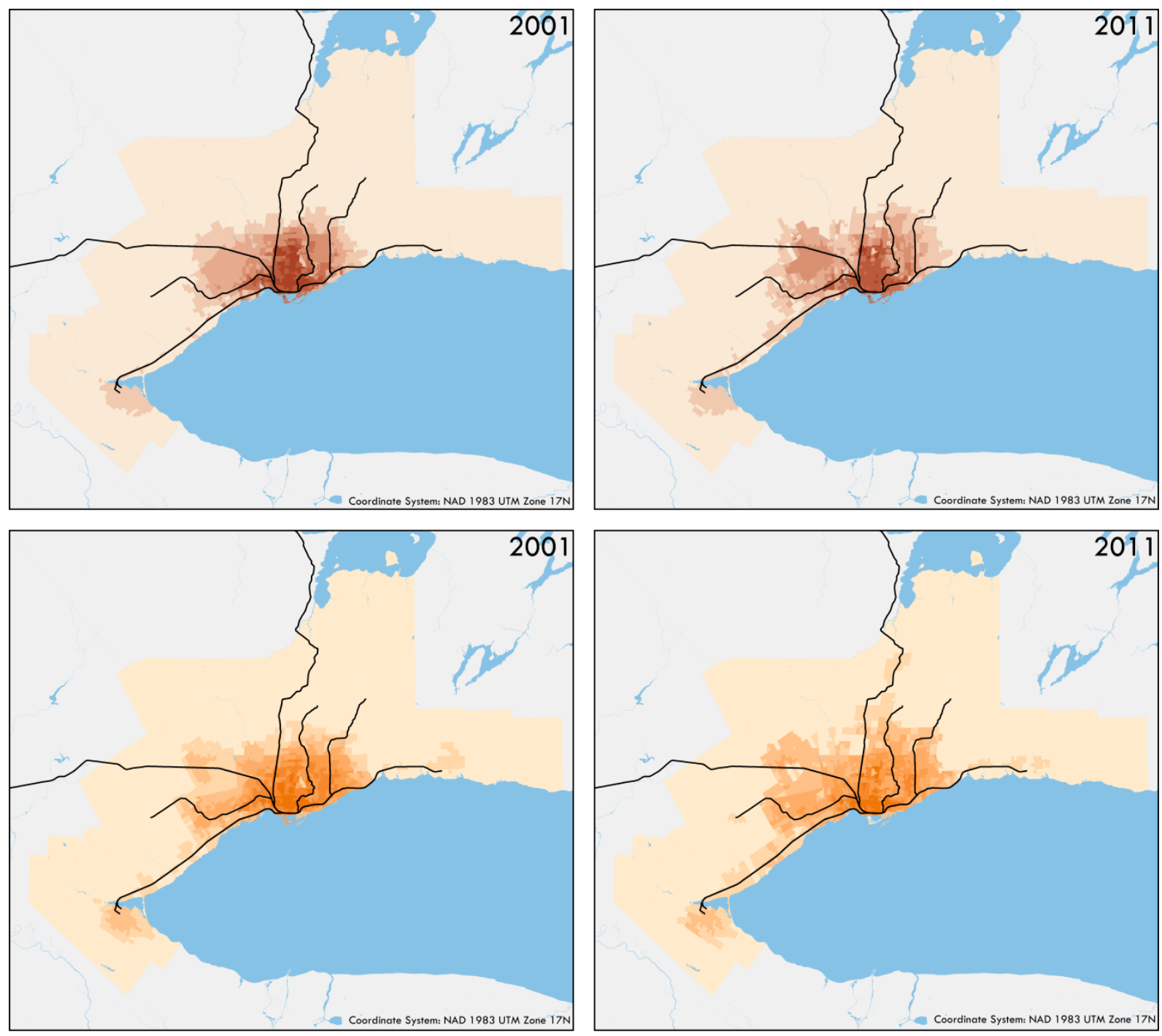

Accessibility to jobs by transit - low to high

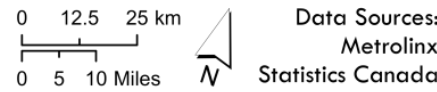

FIGURE 3 Accessibility to jobs and the labor force by public transport

\subsection{Accessibility, commute duration and development}

Several regression models were developed in order to analyze the association between accessibility, commute duration, and economic development and test our two AOD hypotheses. A first, cross-sectional, model predicts average commute duration in 2001 based on accessibility in 2001 and a dummy variable for the Hamilton CMA. A dummy variable for Hamilton was introduced to reflect that residents of census tracts in the Hamilton CMA are more likely to commute to Hamilton than Toronto, thus their commute time is, on average, lower than in the Toronto or Oshawa census metropolitan areas. 
A second model, to test if the relationship between commute duration and accessibility also holds over time, predicts commute time in 2011 based on commute time and accessibility in 2001, and changes in accessibility levels between 2001 and 2011. Levels of accessibility in 2001 were included as it is assumed that the initial situation will influence how changes occur (64). Model 1 and 2 together thus examine the link between accessibility and commuting behavior, in order to validate our first AOD hypothesis, namely that inhabitants of AOD areas with high accessibility to jobs and low accessibility to the labor force experience the lowest commute times.

A third model was developed to assess the second AOD hypothesis, with open area acting as a proxy for development. The same model specification as the second model is used: open area in 2011 is predicted based on open area and accessibility in 2001, and changes in accessibility between the two years. In order to disentangle the separate effects of labor and employment accessibility on attracting residential, commercial, and industrial development, two extra regressions were performed: one predicting job density and the other predicting population density. Descriptive statistics of the variables used in the different models are shown in table 1.

TABLE 1 Descriptive statistics for commute duration, accessibility and development data

\begin{tabular}{|c|c|c|c|}
\hline Variable & Description & Mean & Standard dev. \\
\hline Commute01 & Average commute time in $2001(\mathrm{~min})$ & 28.58 & 6.55 \\
\hline Commute11 & Average commute time in 2011 (min) & 31.29 & 4.25 \\
\hline Access 01 to Jobs by Car & Accessibility to jobs by car in 30 minutes in 2001 (\%) & 20.12 & 12.25 \\
\hline Access 01 to Workers by Car & Accessibility to workers by car in 30 minutes in $2001(\%)$ & 20.75 & 6.86 \\
\hline Access 01 to Jobs by PT & Accessibility to jobs by PT in 45 minutes in $2001(\%)$ & 8.90 & 9.97 \\
\hline Access 01 to Workers by PT & Accessibility to workers by PT in 45 minutes in $2001(\%)$ & 7.53 & 6.79 \\
\hline Access 11 to Jobs by Car & Accessibility to jobs by car in 30 minutes in $2011(\%)$ & 30.97 & 20.24 \\
\hline Access 11 to Workers by Car & Accessibility to workers by car in 30 minutes in 2011 (\%) & 29.26 & 10.36 \\
\hline Access 11 to Jobs by PT & Accessibility to jobs by PT in 45 minutes in $2011(\%)$ & 8.17 & 8.62 \\
\hline Access 11 to Workers by PT & Accessibility to workers by PT in 45 minutes in 2011 (\%) & 6.32 & 5.20 \\
\hline Ch. Commute & Change in commute time ( $\mathrm{min})$ & 2.71 & 4.70 \\
\hline Ch. Access to Jobs Car & Change in access to jobs by car $(\%)$ & 10.84 & 10.17 \\
\hline Ch. Access to Workers by Car & Change in access to workers by car (\%) & 16.74 & 7.59 \\
\hline Ch. Access to Jobs by PT & Change in access to jobs by PT (\%) & -0.73 & 3.34 \\
\hline Ch. Access to Workers by PT & Change in access to workers by PT (\%) & -1.21 & 2.67 \\
\hline OpenArea01 & Percentage of open area in $2001(\%)$ & 14.61 & 15.92 \\
\hline OpenArea11 & Percentage of open area in $2011(\%)$ & 14.57 & 24.13 \\
\hline JobDens01 & Job density in $2001\left(\right.$ jobs $\left./ \mathrm{km}^{2}\right)$ & 181.45 & 526.07 \\
\hline JobDens11 & Job density in 2011 (jobs $\left./ \mathrm{km}^{2}\right)$ & 164.64 & 544.94 \\
\hline PopDens01 & Population density in 2001 (population $/ \mathrm{km}^{2}$ ) & 4337.34 & 4781.05 \\
\hline PopDens11 & Population density in 2011 (population $/ \mathrm{km}^{2}$ ) & 4903.45 & 5285.02 \\
\hline
\end{tabular}


The results of the model associating average commute duration in 2001 and accessibility are shown in table 2 . Note that accessibility by public transport was not included in this model due to collinearity with accessibility by car. A separate model was tested for public transport accessibility and resulted in similar conclusions, but was excluded from the analysis due to its similarity with the reported model.

Higher accessibility to jobs is related to shorter commute times, ceteris paribus, while a higher accessibility to the labor force is related to longer commute times, all else equal, which is consistent with the findings from Levinson (1998). In absolute terms, an extra 100,000 accessible jobs is related to a decrease in commute time of 0.48 minutes $(-0.14$ minutes per percent), while an extra 100,000 workers accessible is related to an increase in average commute duration of 0.87 minutes ( 0.27 minutes per percent). These results corroborate the first AOD hypothesis: AOD areas with high accessibility to jobs and low accessibility to the labor force have shorter average commute times than the rest of the region.

The dummy variable for Hamilton shows that, all else equal, commute time in the Hamilton census metropolitan area is 6.4 minutes shorter. Note that accessibility levels also influence the predicted commute duration in Hamilton. Evaluated at the average accessibility levels for Hamilton (9\% of all jobs accessible by car, and $12 \%$ of all workers accessible by car), census tracts in Hamilton have an average predicted commute duration of 22.2 minutes, 6.4 minutes less than the predicted average for the Toronto census metropolitan area.

TABLE 2 Regression model predicting average commute duration in 2001

\begin{tabular}{|c|c|c|c|}
\hline Variable & Coefficient & Sig. & 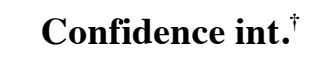 \\
\hline Intercept & 26.5799 & $* * *$ & {$[25.3558,27.8040]$} \\
\hline Access01 to Jobs by Car & -0.1411 & $* * *$ & {$[-0.1699, \quad-0.1124]$} \\
\hline Access01 to Workers by Car & 0.2722 & $* * *$ & {$[0.2178$,} \\
\hline Hamilton & -6.3950 & $* * *$ & {$[-7.4930$} \\
\hline Adjusted $\mathrm{R}^{2}$ & \multicolumn{3}{|c|}{0.2212} \\
\hline
\end{tabular}

The results of the temporal model relating commute time and accessibility are shown in table 3 . Almost $60 \%$ of the total variation in commute times in 2011 is explained by this model. The coefficients for accessibility in 2001 have the expected signs and statistical significance: accessibility to jobs in 2001 is associated with a shorter commute time, while accessibility to the labor force is related to a longer commute duration. The statistical significance of both coefficients could be related to a time lag between accessibility levels and commute patterns adjusting themselves to the new situation, i.e., commute patterns in 2001 were not yet in equilibrium with respect to 2001 accessibility. 
Unlike the cross-sectional model, the effects of both changes in accessibility by public transport and car can be investigated separately, as their changes are no longer correlated. Notably, only changes in accessibility to workers by car and accessibility to jobs by public transport are statistically significant predictors of average commute duration in 2011. These results confirm that the first AOD hypothesis also holds over time. An increase in the change in accessibility of $1 \%$ of all workers by car is associated with a 0.2 minute longer commute, while a $1 \%$ higher change in accessibility by public transport to all jobs is associated with a 0.1 minute shorter commute. Interestingly, the relative magnitudes of both coefficients are reversed compared to the cross-sectional model.

The two coefficients for change in accessibility to jobs by car, and to workers by public transport were found to be not statistically significant. We hypothesize that this is related to the maturity of the transport network in the region. Small changes to the network can no longer induce large impacts on accessibility levels (65), resulting in diminishing returns to the outcomes of transport investments (52).

TABLE 3 Commute time and open area in 2011 fitted to accessibility in 2001 and changes in accessibility between 2001 and 2011

Commute duration in 2011

Open area in 2011

\begin{tabular}{|c|c|c|c|c|c|c|}
\hline Variable & Coefficient & Sig. & Confidence int. ${ }^{\dagger}$ & Coefficient & Sig. & Confidence int. ${ }^{\dagger}$ \\
\hline Intercept & 17.8976 & $* * *$ & {$[17.0579,18.7372]$} & 21.3201 & $* * *$ & {$[17.9573,24.6829]$} \\
\hline Access 01 to Jobs by Car & -0.1027 & $* * *$ & {$[-0.1250,-0.0804]$} & -0.1948 & $* *$ & {$[-0.3185,-0.0710]$} \\
\hline Access 01 to Workers by Car & 0.0793 & $* * *$ & {$[0.04652,0.1122]$} & -0.6212 & $* * *$ & {$[-0.8162,-0.4262]$} \\
\hline Ch. Access to Jobs Car & -0.0093 & & {$[-0.0306,0.0121]$} & 0.0251 & & {$[-0.0989,0.1490]$} \\
\hline Ch. Access to Workers by Car & 0.2139 & $* * *$ & {$[0.1745,0.2532]$} & -0.0595 & & {$[-0.2875,0.1685]$} \\
\hline Ch. Access to Jobs by PT & -0.1083 & $* * *$ & {$[-0.1713,-0.0453]$} & 0.2876 & & {$[-0.0810,0.6561]$} \\
\hline Ch. Access to Workers by PT & -0.0652 & & {$[-0.1558,0.0254]$} & -0.6645 & $*$ & {$[-1.1883,-0.14075]$} \\
\hline Commute 01 & 0.3561 & $* * *$ & {$[0.3295,0.3826]$} & & & \\
\hline OpenArea01 & & & & 0.4958 & $* * *$ & {$[0.4633,0.5282]$} \\
\hline Adjusted $\mathrm{R}^{2}$ & \multicolumn{3}{|c|}{0.5922} & \multicolumn{3}{|c|}{0.5459} \\
\hline
\end{tabular}

Dependent Variables: Average commute duration and open area in 2011

$* 90 \%$ significance level I ** 95\% significance level I*** 99\% significance level

$\dagger 95 \%$ confidence interval

The results for the model predicting open area in each census tract in 2011 can be seen in table 3 , explaining $55 \%$ of all variation in open space. The statistically significant coefficients for accessibility in 2001 corroborate the second AOD hypothesis: accessibility to jobs and workers in 2001 are associated with decreases in open area. One extra percent of accessibility to jobs by car in 2001 is associated with a $0.19 \%$ reduction in open space, and an extra percent of accessibility to workers is related to a $0.62 \%$ decrease in open space. Residential, commercial, and industrial development thus seems to be attracted to AOD areas. 
Changes in accessibility levels, except for the change in worker accessibility by public transport, are not statistically significant predictors of open space in 2011. Two possible explanations exist. First, location choices do not occur often due to the associated capital costs, thus there exists a substantial time lag between accessibility levels changing and location choice. A study period encompassing only 10 years will therefore not be able to fully capture these long-term decisions, especially as it is unknown when each accessibility change occurred. It is also expected that firms, rather than individuals, are more sensitive to changes in accessibility to jobs and workers, and are more prone to change their locations (as residents also place high value on access to other opportunities, such as schools, shops, and social networks),. The statistically significant coefficient for the change in accessibility to workers by transit corroborates this, as it is expected that access to workers is an attractor in firm location behavior. As only the change in accessibility by public transport is statistically significant, we can conclude that firms in the GTHA are more likely to locate near areas where transit service, instead of car accessibility, increases. Although this relationship might depend on the business sector and their associated transport costs for their products and employees, it could be indicative of a paradigm shift in the way (some) enterprises expect their employees or customers to travel. Second, as some areas are almost fully built, changes in accessibility in these neighborhoods can no longer reduce open space and can therefore not be captured by the model.

To resolve this second possibility, and to confirm the hypothesis about firm and individual behavior mentioned above, two extra models were computed, predicting job and population density in 2011. These models again confirm the second AOD hypothesis: job density increased more in areas where baseline accessibility to workers was highest, whereas population density grew considerably more in areas where 2001 accessibility to jobs was highest. This corroborates the hypotheses that firms are attracted to where workers and customers are located, whereas individuals are more likely to choose a home with high access to job opportunities.

TABLE 4 Job and population density in 2011 fitted to accessibility in 2001 and changes in accessibility between 2001 and 2011

\begin{tabular}{|c|c|c|c|c|c|c|}
\hline \multirow[b]{2}{*}{ Variable } & \multicolumn{3}{|c|}{ Job density in 2011} & \multicolumn{3}{|c|}{ Population density in 2011} \\
\hline & Coefficient & Sig. & Confidence int. ${ }^{\dagger}$ & Coefficient & Sig. & Confidence int. ${ }^{\dagger}$ \\
\hline Intercept & -31.9827 & $*$ & {$[-62.2608,-1.7045]$} & 81.3165 & & {$[-379.6737,542.3068]$} \\
\hline Access01 to Jobs by Car & -1.2361 & & {$[-2.5445, \quad 0.0724]$} & 21.3944 & $*$ & {$[1.9579, \quad 40.8308]$} \\
\hline Access 01 to Workers by Car & 2.1506 & $*$ & {$[0.1992,4.1020]$} & -21.9910 & & {$[-51.3465, \quad 7.3645]$} \\
\hline Ch. Access to Jobs Car & 0.4887 & & {$[-0.7560,1.7333]$} & -23.0279 & $*$ & {$[-41.8525, \quad-4.2032]$} \\
\hline Ch. Access to Workers by Car & -0.0960 & & {$[-2.3794, \quad 2.1874]$} & 67.2478 & $* * *$ & {$[32.6678,101.8279]$} \\
\hline Ch. Access to Jobs by PT & -1.6380 & & {$[-5.3603,2.0844]$} & -37.1115 & & {$[-93.4974, \quad 19.2743]$} \\
\hline Ch. Access to Workers by PT & 8.4400 & $* *$ & {$[3.2029,13.6772]$} & 174.8577 & $* * *$ & {$[95.6686$} \\
\hline JobDensity01 & 1.0042 & $* * *$ & {$[0.9853,1.0231]$} & & & \\
\hline PopDensity01 & & & & 0.9584 & $* * *$ & {$[0.9259$} \\
\hline Adjusted $\mathrm{R}^{2}$ & \multicolumn{3}{|c|}{0.931} & \multicolumn{3}{|c|}{0.787} \\
\hline
\end{tabular}

Dependent Variables: Average commute duration and open area in 2011

* 90\% significance level I ** 95\% significance level I *** 99\% significance level 
$\dagger 95 \%$ confidence interval4. CONCLUSION

AOD, a strategy balancing accessibility to employment and the labor force in order to foster an environment conducive to development, has been shown to be associated with changing commute times and economic development. Unlike TOD, AOD leverages the relationship between transport and land use patterns by explicitly considering the functional connection between local and regional transport investments and local and regional land use.

The regression models in our study show that AOD brings two tangible benefits to neighborhoods. First, by influencing accessibility to jobs and workers, average commute times can be adjusted across neighborhoods: increases in accessibility to jobs are related to decreases in commute duration, while increases in accessibility to the labor force are associated with longer average commute times. Second, higher accessibility to employment and/or the labor force is associated with residential, commercial, and industrial development. In a case study in the Greater Toronto and Hamilton Area, we find that high accessibility acts as an attracting force in firm and residential location behavior. Areas developed as AOD are thus characterized by shorter commute times and higher development potential than the rest of the region. Investments aiming to develop successful TODs should therefore take into account AOD principles, and, in order to ensure a successful TOD, measure the impacts of new transport or land use plans in terms of accessibility to both employment opportunities and the labor force.

\section{ACKNOWLEDGEMENTS}

This research was funded by the Social Sciences and Humanities Research Council of Canada and the Natural Sciences and Engineering Research Council of Canada. We would like to thank David King, Nicholas Day and Joshua Engel-Yan from Metrolinx for providing the travel time matrix in 2001. 


\section{References}

[1] Curtis, C., J. Renne, and L. Bertolini. Transit-oriented development: Making it happen. Ashgate, Burlington, VT, 2009.

[2] Papa, E., and L. Bertolini. Accessibility and Transit-Oriented Development in European metropolitan areas. Journal of Transport Geography, Vol. 47, 2015, pp. 70 - 83.

[3] Ratner, K., and A. Goetz. The reshaping of land use and urban form in Denver through transit-oriented development. Cities, Vol. 30, 2013, pp. 31 - 46.

[4] Cervero, R., F. Christopher, and S. Murphy. Transit-oriented development and joint development in the United States: A literature review.In Transportation Research Board, National Research Council, Washington, DC, 2002.

[5] Calthorpe, P. The next American metropolis: Ecology, community, and the American Dream. Princeton Architectural Press, Princeton, 1993.

[6] City of Denver. Transit oriented development strategic plan.In, 2014.

[7] Gilat, M., and J. Sussman. Coordinated transportation and land use planning in the developing world: Case of Mexico City. Transportation Research Record, No. 1859, 2003, pp. 102 - 109.

[8] Cervero, R., S. Murphy, C. Ferrell, N. Goguts, G. B. Arrington, J. Boroski, J. Smith-Heimer, R. Golem, P. Peninger, E. Nakajima, E. Chui, R. Dunphy, M. Myers, S. McKay, and N. Witenstein. Transit oriented development in America: experiences, challenges, and prospects. National Academy Press, Washington, DC, 2004.

[9] Kamruzzaman, M., F. Shatu, J. Hine, and G. Turrell. Commuting mode choice in transit oriented development: Disentangling the effects of competitive neighbourhoods, travel attitudes, and selfselection. Transport Policy, Vol. 42, 2015, pp. 187 - 196.

[10] Bertolini, L., C. Curtis, and J. Renne. Station area projects in Europe and beyond: Towards transit oriented development? Built Environment, Vol. 38, No. 1, 2012, pp. 31 - 50.

[11] Jacobson, J., and A. Forsyth. Seven American TODs: Good practices for urban design in TransitOriented Development projects. Journal of Transport and Land Use, Vol. 1, No. 2, 2008, pp. 51-88.

[12] Duncan, M. The impact of transit-oriented development on housing prices in San Diego, CA. Urban Studies, Vol. 48, No. 1, 2011, pp. 101 -127.

[13] Renne, J. From transit-adjacent to transit-oriented development. Local Environment, Vol. 14, No. 1, 2009, pp. 1 - 15.

[14] Mathur, S., and C. Ferrell. Measuring the impact of sub-urban transit-oriented developments on single-family home values. Transportation Research Part A, Vol. 47, 2013, pp. 42 - 55.

[15] Chatman, D. Transit-oriented development and household travel: A study of California cities.In, California Department of Transportation, Los Angeles, CA, 2006.

[16] Langlois, M., D. van Lierop, R. Wasfi, and A. El-Geneidy. Chasing sustainability: Do new TOD residents adopt more sustainable modes of transportation? Transportation Research Record, No. 2531, 2015 , pp. $83-92$.

[17] Chatman, D. Does TOD Need the T? Journal of the American Planning Association, Vol. 79, No. 1, 2013, pp. 17 - 31.

[18] Belzer, D., and G. Autler. Transit oriented development: Moving from rhetoric to reality.In, The Brookings Institution Center on Urban and Metropolitan Policy, Washington, DC, 2002.

[19] Boarnet, M. A broader context for land use and travel behavior, and a research agenda. Journal of the American Planning Association, Vol. 77, No. 3, 2011, pp. 197 - 213.

[20] Boisjoly, G., and A. El-Geneidy. How to get there? A critical assessment of accessibility objectives and indicators in metropolitan transportation plans. Transport Policy, Vol. 55, 2017, pp. 38 - 50.

[21] Geurs, K., and B. van Wee. Accessibility evaluation of land-use and transport strategies: Review and research directions. Journal of Transport Geography, Vol. 12, No. 2, 2004, pp. 127 - 140.

[22] Handy, S., and D. Niemeier. Measuring accessibility: an exploration of issues and alternatives. Environment and planning A, Vol. 29, No. 7, 1997, pp. 1175 - 1194. 
[23] Hansen, W. How accessibility shapes land use. Journal of the American Institute of Planners, Vol. 25, No. 2, 1959, pp. 73 - 76.

[24] Wickstrom, G. Defining balanced transportation: A question of opprtunity. Traffic Quarterly, Vol. 25, No. 3, 1971, pp. 337-349.

[25] El-Geneidy, A., and D. Levinson. Access to destinations: Development of accessibility measures.In, Department of Civil Engineering, University of Minnesota, Minneapolis, MN, 2006.

[26] El-Geneidy, A., D. van Lierop, and R. Wasfi. Do people value bicycle sharing? A multilevel longitudinal analysis capturing the impact of bicycle sharing on residential sales in Montreal, Canada. Transport Policy, Vol. 51, 2016, pp. 174 - 181.

[27] Lucas, K. Transport and social exclusion: Where are we now? Transport Policy, Vol. 20, 2012, pp. $105-113$.

[28] Korsu, E., and S. Wenglenski. Job accessibility, residential segregation, and risk of long-term unemployment in the Paris region. Urban Studies, Vol. 47, No. 11, 2010, pp. 2279 - 2324.

[29] Andersson, F., J. Haltiwanger, M. Kutzbach, H. Pollakowski, and D. Weinberg. Job displacement and the duration of joblessness: The role of spatial mismatch.In, National Bureau of Economic Research, Cambridge, MA, 2014.

[30] Holl, A. Transport infrastructure, agglomeration economies, and firm birth: Empirical evidence from Portugal. Journal of Regional Science, Vol. 44, No. 4, 2004, pp. 693 - 712.

[31] Owen, A., and D. Levinson. Modeling the commute mode share of transit using continuous accessibility to jobs. Transportation Research Part A, Vol. 74, 2015, pp. 110 - 122.

[32] Bocarejo, J., and D. Oviedo. Transport accessibility and social inequities: A tool for identification of mobility needs and evaluation of transport investments. Journal of Transport Geography, Vol. 24, 2012, pp. 142-154.

[33] Delmelle, E., and I. Casas. Evaluating the spatial equity of bus rapid transit-based accessibility patterns in a developing country: The case of Cali, Colombia. Transport Policy, Vol. 20, 2012, pp. 36-46.

[34] Foth, N., K. Manaugh, and A. El-Geneidy. Towards equitable transit: Examining transit accessibility and social need in Toronto, Canada, 1996 - 2006. Journal of Transport Geography, Vol. 29, 2013, pp. 1 10 .

[35] Golub, A., and K. Martens. Using principles of justice to assess the modal equity of regional transportation plans. Journal of Transport Geography, Vol. 41, 2014, pp. 10-20.

[36] Guzman, L., D. Oviedo, and C. Rivera. Assessing equity in transport accessibility to work and study:

The Bogotá region. Journal of Transport Geography, Vol. 58, 2017, pp. 236 - 246.

[37] Kain, J. The journey-to-work as a determinant of residential location. Papers in Regional Science, Vol. 9, No. 1, 1962, pp. 137 - 160.

[38] Alonso, W. Location and Land Use. Harvard University Press, Cambridge, MA, 1964.

[39] Anas, A., and L. Moses. Mode choice, transport structure and urban land use. Journal of Urban Economics, Vol. 6, 1977.

[40] Mills, E. An aggregative model of resource allocation in a metropolitan area. The American Economic Review, Vol. 57, No. 2, 1967, pp. 197 - 210.

[41] Forkenbrock, D., S. Mathur, and L. Schweitzer. Transportation investment and urban land use patterns.In, Public Policy Center, The University of Iowa, 2001.

[42] Giuliano, G. Land use impacts of transportation investments: Highway and Transit.In The Geography of Urban Transportation, The Guilford Press, New York, NY, 2004.

[43] European Commision. High-speed Europe.In, Directorate-General for Mobility and Transport, 2010.

[44] Smolka, M. Implementing value capture in Latin America: Policies and tools for urban development.In, Lincoln Institute of Land Policy, Cambridge, MA, 2013.

[45] Transport for London. Land value capture.In, Transport for London, London, 2017.

[46] Salon, D., and S. Shewmake. Opportunities for value capture to fund public transport: A comprehensive review of the literature with a focus on East Asia.In, Institute for Transportation \& Development Policy, 2014. 
[47] Warade, R. The accessibility and development impacts of new transit infrastructure: The circle line in Chicago.In Department of Urban Studies and Planning, No. Master in City Planning, Massachusetts Institute of Technology, Boston, MA, 2007.

[48] Banister, D., and J. Berechman. Transport investment and economic development. UCL Press, London, UK, 2000.

[49] Levinson, D. Accessibility and the journey to work Journal of Transport Geography, Vol. 6, No. 1, 1998, pp. 11-21.

[50] Franklin, J., and P. Waddell. A hedonic regression of home prices in King County, Washington, using activity-specific accessibility measures.In Transportation Research Board 82nd Annual Meeting, Washington, DC, 2003.

[51] Martínez, L., and J. Viegas. Effects of transportation accessibility on residential property values. Transportation Research Record, No. 2115, 2009, pp. 127 - 137.

[52] Iacono, M., and D. Levinson. Accessibility dynamics and location premia: Do land values follow accessibility changes? Urban Studies, Vol. 54, No. 2, 2015, pp. 364 - 381.

[53] Du, H., and C. Mulley. Relationship between transport accessibility and land value. Transportation Research Record, No. 1977, 2006, pp. 197 - 205.

[54] Mejia-Dorantes, L., A. Paez, and J. Vassallo. Transportation infrastructure impacts on firm location: The effect of a new metro line in the suburbs of Madrid. Journal of Transport Geography, Vol. 22, 2012, pp. $236-250$.

[55] Padeiro, M. Transport infrastructures and employment growth in the Paris metropolitan margins. Journal of Transport Geography, Vol. 31, 2013, pp. 44 - 53.

[56] Ozbay, K., D. Ozmen-Ertekin, and J. Berechman. Empirical analysis of relationship between accessibility and economic development. Journal of Urban Planning and Development, Vol. 129, No. 2, 2003, pp. 97 - 119.

[57] Shen, Y., J. de Abreu e Silva, and L. M. Martínez. Assessing land cover change in large urban areas resulting from High-speed Rail: A case study of Madrid Atocha railway station from 1990 to 2006. Journal of Transport Geography, Vol. 41, 2014, pp. 184 - 196.

[58] Farber, S., and M. Grandez Marino. Transit accessibility, land development and socioeconomic priority: A typology of planned station catchment areas in the Greater Toronto and Hamilton Area. Journal of Transport and Land Use, Vol. 10, No. 1, 2017, pp. 33 - 56.

[59] Cervero, R. Jobs-housing balancing and regional mobility. Journal of the American Planning Association, Vol. 55, No. 2, 1989, pp. 136 - 150.

[60] ---. Jobs-housing balance revisited: trends and impacts in the San Francisco Bay Area. Journal of the American Planning Association, Vol. 62, No. 4, 1996, pp. 492 - 511.

[61] Levinson, D., B. Marion, A. Owen, and M. Cui. The City is flatter: Changing patterns of job and labor access. Cities, Vol. 60, 2017, pp. 124 - 138.

[62] Statistics Canada. Labour force survey estimates (LFS), employment by census metropolitan area CANSIM table 282-0130. http://www5.statcan.gc.ca/cansim/a26?lang=eng\&retrLang=eng\&id=2820130\&\&pattern=\&stByVal=1\& p1=1\&p2=31\& tabMode=dataTable \&csid=. Accessed 6 July 2017, 2017.

[63] ---. Mode of transportation and average commuting time to get to work in Montréal, Toronto and Vancouver census metropolitan areas, http://www.statcan.gc.ca/pub/11-008-x/2011002/t/11531/tblbxeng.htm. http://www.statcan.gc.ca/pub/11-008-x/2011002/t/11531/tblbx-eng.htm. Accessed June 15, 2017.

[64] Putnam, S. H. Integrated urban models. Pion, London, 1983.

[65] Gómez-Ibáñez, J. Transportation policy as a tool for shaping metropolitan development.In Research in Transportation Economics, Volume 2, JAI Press, Greenwich, CT, 1985. pp. 55 - 81. 